offer of his proposition deserves to be regarded as a valid one, it will not only avoid the necessity of any more experimental evidence than we already posses; of the nature of gravitative action, but it will also afford at the same time a satisfactory confirma. tion of the kind of ethereal explanation of gravitation of which M. Pictet is in search.

I have been delayed hitherto in publishing my views of the primary character of thermo-dynamical principles by difficulties which at the outset attended their applications to explain the experimental phenomena of conduction and radiation. These difficulties, however, and others naturally incident to the development of a new physical conception, I believe that I have satisfactorily mastered and overcome. But I anticipate the needs of much greater expansions in the theory before it will avail as completely as in those important cases, to include and demonstrate properties of specific and latent heats, and of dilatation, and the other thermal phenomena of fusion and evaporation, and of vapour tension, to which M. Pictet has found for his theory such useful applications.

Taking his departure from an entirely different common principle of thermal actions from that with which $I$ set out, the results of M. Pictet's researches will yet, I believe, accord intimately, wherever the two parallel method; have a common meeting-point, with my own deductions. I accordingly entertain great hopes of recognising among his examples of conformity to a common law and method, links and steps of demionstration in a complete theory of the properties of heat, in phases of its action where physical axioms not exactly akin to his own fail to furnish me with sufficient explanations of them; in the same way that it has afforded me great pleasure to offer full corroboration of M. Pictet's views, from my own inquiries, at a point where his theoretical hypotheses have proved insufficient to cope with an exceedingly extensive and general provision of kinetic laws, much more comprehensive in its physical relations than those mechanical deportments of which we observe the properties and laws in ponderable matter, when it is not under the more profoundly modifying and affecting influence of the all-energising power and all-pervading agency of heat.

Collingwood, Hawkhurst, July 29 A. S. HERSCHEL

\section{Cailletet's Pump for Condensing Gas}

AT page 308 of your last number you mention a pump invented by M. Cailletet for condensing gases, in which he uses mercury as a fluid piston, in order to fill every interstice of the pump barrel, and so expel the last atom of gas; of course, in this case, he would use an ordinary plunger pump, with both the inlet and outlet valves at the top, and the proper quantity of mercury in the barrel, so as to fill it completely in the down. stroke of the plunger or piston.

It is curious that a similar pump is figured in the first volume of the Mechanics Masazine, 1823, page 232, as invented by Henry Russell; and I have always understood that a modification of this was used by David Gordon at the unfortunate "Portable Oil Gas Co.", to condense gas into the reservoir from which his lamps were filled. The patents are Gordon and Heard, 439I-1819, and David Gordon, 4940-1824; a crmpany was formed at the time for using his lamps, and was worked for a few years, but the royalties having much exceeded the profits, the Company came to grief.

3 , Lorton Terrace, Notting Hill, August 2

\section{Spectrum of the Light of the Glowworm}

WHEN the subject of the phosphorescence of the Lanıpyrida came under discus ion at the meeting of the Entomological Society of London on February 4, I880 (Proc. Ent. Soc., I880, p. iii.) Mr. Meldola stated that "Some years ago he had examined the spectrum of the glowworm, and found that it was continuous, being rich in blue and green rays, and comparatively poor in red and yellow." This substantially confirms the observation of Sir John Conroy, although Mr. Meldola gives no measurements.

Canonbury, August 5

\section{White Ants' Nests}

I OBSFRVE in NATURE, vol. xxvi. p. 72, from line 13 to 35 inclusive, some remarks regarding the composition of the inner of the two distinct structures composing an ant hill, and that though the composition of the inner parts was chemically the same as wood, it was structureless, and its origin not known or understood.

I believe it is simply composed of the excreted refuse of the

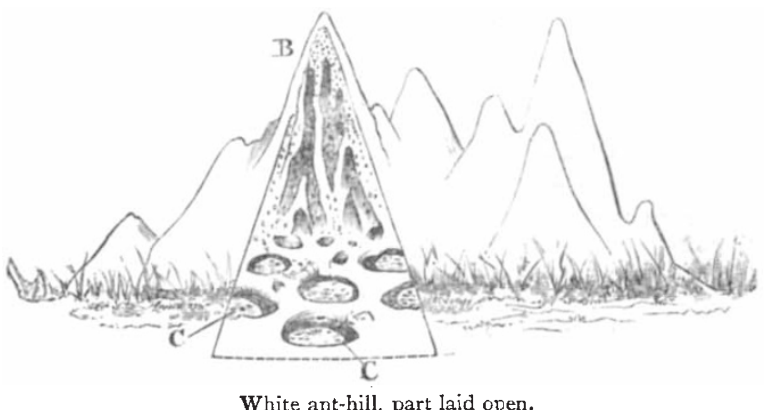

wood on which they feed, and formed into sub-spherical comb. in which the young are generally found. The walls of the ant hill are of pure clay perforated with passages; towards the centre there are large chambers in which these combs are

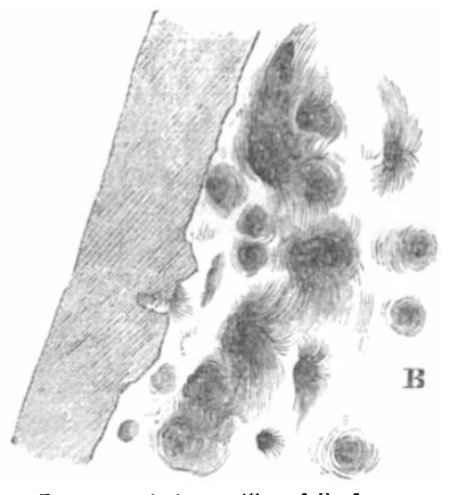

B.-Part of clay walling, full of passages.

constructed, and they are full of passages and small chambers, the walls about I-20th of an inch thick. I send some rough sketches that may serve to illustrate these, in case they may be worth insertion.

It is no wonder these combs are structureless and yet of the
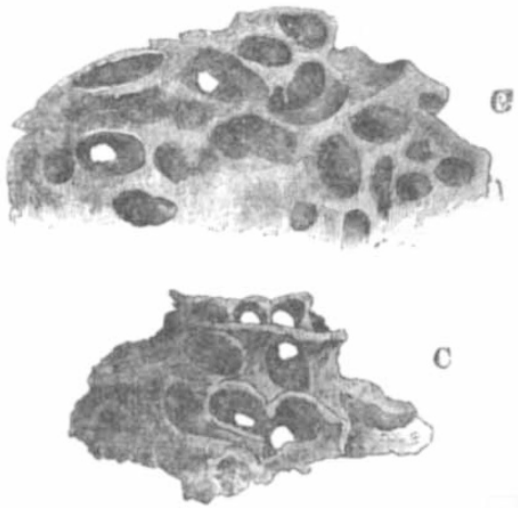

C. - Pari of a comb, full of chambers

same chemical composition as wood. If a box full of papers or books is attacked the results are only too well known to those living in the tropics.

Asam, June 18

S. E. Peal

\section{Voice in Lizards}

I HAVE been much surprised to see by the recent letters in NATURE that there was any doubt as to the lizard having a voice. I have so often heard and seen a lizard uttering its peculiar 